\title{
Plant conservation at the crossroads
}

\author{
STEPHEN D. HOPPER
}

In 2010, the International Year of Biodiversity, a collaboration between the Royal Botanic Gardens Kew, the Natural History Museum, IUCN and other partners produced the Sampled Red List Index, which established that a fifth of plant species are threatened. This proportion is the same as that for mammals, more than for birds, and less than for amphibians. Of course, there is an order of magnitude difference, with more than 380,000 vascular plants recorded and 2,000 new species having been described each year over the past 2 decades.

There is, understandably, a significant knowledge gap regarding our green companions as well. A third of plant species are insufficiently known for a reliable conservation assessment to be made. What we do know is that, among larger groups, gymnosperms (especially cycads) and monocotyledons have the most threatened species. We know that the greatest numbers of threatened plants are in the tropics, especially forests, and habitats with a Mediterranean climate. We also know that human use of land and waters contributes to $80 \%$ of the threats faced by plant diversity.

Fortunately, there is a growing global cadre of plant conservation biologists helping to provide the missing information. This issue of Oryx exemplifies the richness of approach and geographical spread of such research.

Martinell et al. (2011) illustrate a recurring theme for threatened plants, many of which are highly localized and poorly known endemics. Their study of Aquilegia paui (Ranunculaceae) in the Parc Natural dels Ports of Spanish Catalonia is one of taxonomic detective work followed by careful field studies establishing where the species occurs. It is a montane endemic confined to the highest summit of the Els Ports massif. Like so many threatened Mediterranean narrow endemics $A$. paui is a rock outcrop specialist, favouring shaded northern slopes on calcareous cliffs and scree. Just four subpopulations are known, distributed across a narrow range of a few kilometres, comprising a total of 338 plants in 2008 . What to do with such a plant in such a difficult, regularly-disturbed habitat is a question addressed by the authors: reinforced habitat protection, translocation to new sites, further field surveys in remote or unexplored sites to search for undocumented populations, biological studies to understand reproductive capacity and population turnover, and managing human impacts such as climbing, and grazing by stock. They also recommend recovery planning following further research.

The A. paui story, above all, is a plea for the importance of taxonomic collections and research as the fundamental

Stephen D. Hopper Royal Botanic Gardens, Kew, Richmond, Surrey, TW9 3AB UK. E-mail s.hopper@kew.org scientific infrastructure underpinning global plant conservation efforts. At a time when herbaria and the teaching of taxonomy and plant diversity are seriously at risk across the world, we should all be moved by the authors' concluding sentence: 'The case of this species is an example of the plight of other potentially neglected rare species that are facing extinction in anonymity because their taxonomic status has been misunderstood or overlooked'

Fenu et al. (2011) highlight another Mediterranean montane local endemic at risk, the daisy Lamyropsis microcephala in Sardinia. A ski run, nomadic grazing and parasitism threaten L. microcephala, which favours north facing slopes of the Gennargentu massif. Careful studies of reproductive biology emphasized the need for seed collection and storage as a key insurance measure. Indeed, this has become a global enterprise in plant conservation, with Kew's Millennium Seed Bank Partnership achieving in 2010 its first 10 year objective-securing seed of $10 \%$ of plant species in storage-in 54 countries of origin backed by a second collection at the Millennium Seed Bank at Wakehurst Place in England. Fenu et al. (2011) highlight the value of population genetic studies to help plan and execute seed collection that aims to conserve maximum genetic diversity. They also undertook a public engagement programme to heighten local awareness for this threatened plant. It is evident that local people as conservation custodians provide the most effective and optimistic outcomes for long-term conservation. Research scientists must engage with local communities if they wish to see that the species studied have a secure future in the wild.

The important role of well-endowed larger botanic gardens in plant conservation is evident in Miller \& Morgan's (2011) account of the 46 native taxa of Boraginales known in Madagascar and the Comoros Islands. More than half (26) of these taxa are threatened, and many occur in poorly studied dry forest. This article is, firstly, an example of the power in conservation assessment of digitized specimen databases, now accessible on the internet but reliant, of course, on continued support for, and maintenance of, the infrastructure provided by herbarium collections. Miller \& Morgan's (2011) protected area analysis also provides an elegant example of the wonder, speed and accuracy of geographical information systems applied to specimen label data in conservation assessment.

There is an extraordinary message of hope emerging from botanical work in Madagascar. With a flora of more than 11,000 species, 90\% endemic, and under enormous pressures from human land and water use, Madagascar epitomizes the tropical conservation challenge. The world's largest botanical gardens, including Missouri, Kew and New York, have combined forces with local and international NGOs and 
other research agencies to accelerate collection, taxonomic description and conservation of this extraordinary flora. Miller \& Morgan (2011) relate the Malagasy President's enlightened commitment, made in 2003, to triple Madagascar's protected area system within 5 years. This happened, an exceptional outcome by any reckoning. It was enabled by the collaborative publication of the Atlas of the Vegetation of Madagascar (Moat \& Smith, 2011), which assembled and analysed much of the newly acquired botanical survey data for the country.

The study of Boraginales illustrates the outcome. An additional six of the 46 endemic species were included in protected areas, taking the number from 30 to 36 . This number would rise again to 43 if additional Proposed Priority Areas for Plant Conservation are declared. The latter cover more of the dry forests of Madagascar, which did not receive as much attention as the rainforests in the recent upgrade of the number and extent of protected areas.

Given the focus on the wet tropics, desert floras are often overlooked by mainstream conservation workers. Hernandez \& Gómez-Hinostrosa (2011) illustrate that this is an oversight in need of rectification. Two-thirds of 121 of the cactus species endemic to the Chihuahuan Desert occur in protected areas. Narrow endemism is, again, a feature of the 44 species excluded from protected areas. Globally, the creation of protected areas has tended towards lands and waters not sequestered for other uses, or selected to represent major habitats and communities but assessed from often coarse vegetation and soil maps combined with survey data for vertebrates. Areas of plant endemism are often excluded, in part because of relatively poor study until recently. Better integration of plant biodiversity data, and less reliance on surrogates such as vegetation maps or vertebrate groups, will be essential for future protected area planning, creation and management.

Budiharta et al. (2011) bring us to the heart of the greatest plant conservation challenge: tropical rainforests. Without a conservation solution here, the prospect of sustainable human existence with biodiversity, and of global warming moderated by the remaining tropical forests, seems questionable. Indonesia's forests are being logged and converted to agriculture (mainly palm oil production), human settlements, and perennial crop and timber plantations at an alarming rate. Budiharta et al. (2011) provide an analysis of what this local manifestation of long-established worldwide human attitudes to land use means for threatened plants. The Indonesian government has set aside c. $13 \%$ of the country's area for protected areas. Yet more than half of these protected areas have ongoing human uses detrimental to their purpose.

Ultimately, as Budiharta et al. (2011) demonstrate for orchids, palms, Amorphothallus and Rafflesia, understanding the biology of plants under threat is essential for their conservation. We should be circumspect in attempting to generalize, and cautious in assuming surrogacy of one group for another in conservation planning. For example, contrary to mainstream ideas in current conservation literature, Budiharta et al. (2011) found that '...invasive alien species, pollution, disease and climate change are not important threats to Indonesian plants'.

I was inspired by delta blues singer Robert Johnston's famous song in offering the title to this Editorial. Plant conservation stands at the crossroads, many of us wondering which way to go. Science, however, has a key role to play, and I remain heartened by the quality and commitment of plant conservationists around the world, so well illustrated by the authors of articles in this issue of Oryx.

\section{References}

Budiharta, S., Widyatmoko, D., Irawati, Wiriadinata, H., Rugayah, Partomihardjo, T. et al. (2011) The processes that threaten Indonesian plants. Oryx, 45, 172-179.

Fenu, G., Mattana, E. \& Bacchetta, G. (2011) Distribution, status and conservation of a Critically Endangered, extremely narrow endemic: Lamyropsis microcephala (Asteraceae) in Sardinia. Oryx, 45, 180-186.

Hernández, H.M. \& Gómez-Hinostrosa, C. (2011) Areas of endemism of Cactaceae and the effectiveness of the protected area network in the Chihuahuan Desert. Oryx, 45, 191-200.

Martinell, M.C., López-Pujol, J., Blanché, C., Molero, J. \& SÀEz, L. (2011) Conservation assessment of Aquilegia paui (Ranunculaceae): a case study of an extremely narrow endemic. Oryx, 45, 187-190.

Miller, J.S. \& Porter Morgan, H.A. (2011) Assessing the effectiveness of Madagascar's changing protected areas system: a case study of threatened Boraginales. Oryx, 45, 201-209.

Mont, J. \& S Mith, P. (eds) (2011) Atlas of the Vegetation of Madagascar. Kew Publishing, Royal Botanic Gardens, Kew, UK. 